\title{
Effects of recombinant protein misfolding and aggregation on bacterial membranes
}

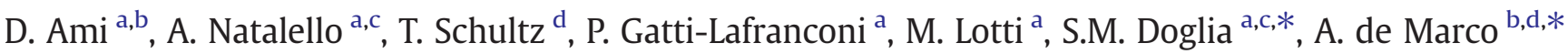 \\ a Department of Biotechnology and Biosciences, University of Milano-Bicocca, Piazza della Scienza 2, 20126 Milan, Italy \\ b IFOM-IEO Campus for Oncogenomics, via Adamello 16, 20139 Milan, Italy \\ c Consorzio Nazionale Interuniversitario per le Scienze fisiche della Materia (CNISM) UdR Milano-Bicocca, via Cozzi 53, 20125 Milan, Italy \\ d Scientific Core Facilities, EMBL, Meyerhofstr. 1, D-69117 Heidelberg, Germany
}

\section{A R T I C L E I N F O}

Article history:

Received 10 July 2008

Received in revised form 9 October 2008

Accepted 23 October 2008

Available online 11 November 2008

\section{Keywords:}

Fourier transform infrared spectroscopy

Membrane lipid

Protein aggregation

Recombinant protein

Stress metabolism

Small chaperone

\begin{abstract}
A B S T R A C T
The expression of recombinant proteins is known to induce a metabolic rearrangement in the host cell. We used aggregation-sensitive model systems to study the effects elicited in Escherichia coli cells by the aggregation of recombinant glutathione-S-transferase and its fusion with the green fluorescent protein that, according to the expression conditions, accumulate intracellularly as soluble protein, or soluble and insoluble aggregates. We show that the folding state of the recombinant protein and the complexity of the intracellular aggregates critically affect the cell response. Specifically, protein misfolding and aggregation induce changes in specific host proteins involved in lipid metabolism and oxidative stress, a reduction in the membrane permeability, as well as a rearrangement of its lipid composition. The temporal evolution of the host cell response and that of the aggregation process pointed out that the misfolded protein and soluble aggregates are responsible for the membrane modifications and the changes in the host protein levels. Interestingly, native recombinant protein and large insoluble aggregates do not seem to activate stress markers and membrane rearrangements.
\end{abstract}

(c) 2008 Elsevier B.V. All rights reserved.

\section{Introduction}

Environmental modifications can alter the cell physiological conditions and induce protein unfolding and aggregation in both bacterial and eukaryotic cells. The presence of aggregates is promptly sensed by cells and triggers specific responses to counteract protein misfolding and its possible toxic effects [1-4]. Thus, protein instability caused by heat and/or osmotic shock induces the production of heatshock proteins and the accumulation of osmolytes $[5,6]$. Similarly, the unfolded protein response in yeast is a consequence of the accumulation of unstable polypeptide intermediates in the endoplasmic reticulum [7].

Protein aggregation inside cells is far from being a simple two-state event, since the same protein may be deposited in cells as aggregates of different complexity [8-10]. Cells do not experience a simple soluble or

Abbreviations: DPH, 1,6-diphenyl-1,3,5-hexatriene; $\mathrm{E}_{3}$, dihidrolipoyl dehydrogenase $\mathrm{E}_{3}$; EM, electron microscopy; FT-IR, Fourier transform infrared spectroscopy; GFP-GST, green fluorescent protein-glutathione-S-transferase; GST, glutathione-S-transferase; IB inclusion body; IPTG, isopropyl $\beta$-D-1-thiogalactopyranoside; NPN, 1-N-phenylnaphtylamine; pETM33-GST vector, GST under T7 promoter; PFL, Pseudomonas fragi lipase; pQE30-GST vector, GST under T5 promoter; SOD, superoxide dismutase; TLC, thin-layer chromatography

* Corresponding authors. S.M. Doglia is to be contacted at tel.: +39 026448 3459; fax: +39 026448 3565. A. de Marco, tel.: +39 02574303 229; fax: +39 02574303 .

E-mail addresses: silviamaria.doglia@unimib.it (S.M. Doglia), ario.demarco@ifom-ieo-campus.it (A. de Marco). insoluble alternative, but are exposed to discrete classes of aggregates differing in the conformational state of the enclosed proteins [8-10]. Interestingly, evidences have been reported that differently structured aggregates have different effects on cells. For instance, in eukaryotes, the soluble aggregates of proteins responsible for neurodegenerative diseases are more toxic than larger assemblies [8].

Heterologous proteins expressed in $E$. coli often aggregate, because the folding capacity of the cell machinery may be limited by the nonphysiological rates of expression. Cells react to this stress through complex and overlapping stress responses [1]. Among these, cells activate the expression of a set of proteins involved in removing the aggregates, such as chaperones, proteases and other folding catalysts [11]. After protein release from aggregates, refolding into their native state can take place [12-14].

In this work, we investigated whether the overexpression of recombinant proteins in bacteria induces responses other than the production/activation of folding helpers and whether the structure of protein aggregates has a role in eliciting these responses. In particular, we focussed on possible variations in the cell membrane, which was already reported to undergo rearrangements upon treatment with compounds able to mimic a heat-shock stress [15-17]. We, therefore, examined the effects of recombinant protein aggregates on cell membranes by choosing, as model systems, the glutathione-Stransferase (GST) and its fusion with the green fluorescent protein (GFP-GST), since it is possible to tune their aggregation by changing the expression conditions. In particular, it has been recently reported that GFP-GST can form soluble and insoluble aggregates of different 
complexity [9]. These experimental systems allow not only the study of the effects on the host cell membranes of a recombinant protein in soluble or aggregated form, but also those of the aggregate conformational states. Indeed, different aggregates have been already found to affect differently phospholipid bilayers [18]. To monitor the correlation among recombinant protein aggregates, cell physiology, and stress parameters, we employed, as a reporter probe, a betagalactosidase gene expressed under the control of an $I b p B$ promoter, specifically activated by misfolded proteins undergoing aggregation $[11,19,20]$. To study lipid changes occurring in intact cells during recombinant protein expression and aggregation, beside conventional biochemical methods, we employed Fourier-transform infrared (FTIR) spectroscopy, a technique that has been widely used to characterize membrane properties and lipid composition [21-23].

Our results indicate that the folding state of the recombinant protein and the complexity of the intracellular aggregates critically affect the cell response, with regard to both the host proteome and the composition and permeability of the cell membrane.

\section{Materials and methods}

\subsection{Cell culture, protein identification and aggregation analysis}

Recombinant glutathione-S-transferase (GST) was expressed in E. coli from plasmids pQE30 (Qiagen; T5 promoter into M15 strain) and pETM33 (T7 promoter into BL21(DE3) strain) [24]. The green fluorescent protein-GST fusion protein (GFP-GST) was obtained using a Gateway vector (Invitrogen) [9]. Co-transformation with the IbpB-promoter/beta-galactosidase vector was performed to monitor in vivo the aggregation of the recombinant protein [11,19]. Bacteria were initially grown at $37^{\circ} \mathrm{C}$ until the cultures reached an $\mathrm{OD}_{600 \mathrm{~nm}}$ of 0.4 and, subsequently, the growth temperature was adjusted in the different experiments to values ranging from $20{ }^{\circ} \mathrm{C}$ to $37{ }^{\circ} \mathrm{C}$. Recombinant expression was induced with $0.1 \mathrm{mM}$ isopropyl $\beta-\mathrm{D}-1$ thiogalactopyranoside (IPTG), when the $\mathrm{OD}_{600 \mathrm{~nm}}$ reached the value of 0.6. Culture samples were collected and fractionated as previously described [24]. The insoluble recombinant protein was quantified after SDS gel separation of the pellet recovered after centrifugation of the bacteria lysate from samples taken at different times during cell culture. The supernatant obtained after lysate centrifugation was used to load the 2D gels. Both 2D runs and mass spectrometry identification and quantification of the separated proteins were performed at the Proteomic Facility of EMBL-Heidelberg.

The sample preparation and the evaluation of the protein aggregation level by beta-galactosidase activity were described in detail in [19]. In particular, the activity of beta-galactosidase was determined spectrophotometrically and expressed in Miller units [25], according to: Miller units $=1000 \times\left(\mathrm{OD}_{420}-1.75 \times \mathrm{OD}_{550}\right) /\left(t \times V \times \mathrm{OD}_{600}\right)$ where $t=$ reaction time in minutes, $V=$ volume of culture assayed in milliliters.

\subsection{Electron microscopy}

Protein samples $(15 \mu \mathrm{M})$ were fixed by dropping $5 \mu \mathrm{L}$ on a grid (Agar Scientific). After $1 \mathrm{~min}$ incubation at room temperature, the excess fluid was removed using filter paper and the unbound protein was washed before the grids were placed on a $50 \mu \mathrm{L}$ drop of $1 \%$ uranyl acetate with the section side downwards. Finally, the grids were dried, placed in the grid-chamber and stored in desiccators before observation with a CM120 BioTwin electron microscope (Philips).

\subsection{Cell membrane permeability and lipid composition}

Cell membrane permeability was estimated analyzing the fluorescence variation of the hydrophobic probe $1-\mathrm{N}$-phenylnaphtylamine (NPN) (Sigma), according to a protocol [15] modified from the original method described by Helander and Mattila-Sandholm [26]. Recombinant protein expression was induced with $0.1 \mathrm{mM}$ IPTG when the cell culture reached the $\mathrm{OD}_{600}$ of 0.4 . Bacteria were then grown at $37^{\circ} \mathrm{C}$ for $90 \mathrm{~min}$ and then $200 \mu \mathrm{L}$ of cell culture were collected and diluted $1: 1$ in $50 \mathrm{mM}$ HEPES containing $5 \mu \mathrm{g} / \mathrm{mL}$ NPN. The uptake of the fluorescent probe was measured after $10 \mathrm{~min}$ incubation at $25{ }^{\circ} \mathrm{C}$, setting the excitation and emission wavelength of the fluorimeter at 350 and $422 \mathrm{~nm}$, respectively.

Membrane lipids were identified after extraction and separation by thin-layer chromatography (TLC) using lipid standards and silica coated TLC plates (Merck Eurolab). Bacteria cultured as described above were centrifuged and resuspended in a 20 fold lower volume of fresh LB medium to increase cell concentration. $1 \mathrm{~mL}$ of concentrated cell suspension was transferred into a screw-capped glass tube and $3.75 \mathrm{~mL}$ of a chloroform/methanol/concentrated $\mathrm{HCl}$ mixture (5:10:0.075) were added. After vortexing, $1 \mathrm{~mL}$ of chloroform was added and the mixture was vortexed again before supplying $1 \mathrm{~mL}$ of $\mathrm{H}_{2} \mathrm{O}$. The suspension was separated in three phases by centrifugation ( 2 min at $1500 \times g$ ). The lowest phase containing the lipid fraction was recovered and after a second extraction in water the lipid fraction was transferred in a $1.5 \mathrm{~mL}$ silicon-coated tube. The solvents were evaporated in a vacuum centrifuge and the pellet resuspended in $10 \mu \mathrm{L}$ of a $1: 1$ chloroform/methanol mixture. $1 \mathrm{mg}$ of standard asolectin was resuspended using the same conditions. A thin layer chromatography plate was activated by incubation $\left(30 \mathrm{~min} \times 100^{\circ} \mathrm{C}\right)$ in the presence of chloroform/methanol/glacial acetic acid/water (60:50:1:4) and the samples were loaded and separated. For their identification the plate was first dried, treated with molybdatphosphoric acid and finally heated at $100{ }^{\circ} \mathrm{C}$ [27].

\subsection{Cell membrane fluidity by fluorescence anisotropy measurements}

Cell membrane fluidity was evaluated by measuring the fluorescence anisotropy of 1,6-diphenyl-1,3,5-hexatriene (DPH) (Molecular Probes) $[28,29]$ on recombinant bacteria transformed with pQE30 or pETM33, before and 90 min after induction. Cells were washed twice with phosphate buffer saline (PBS, $\mathrm{pH}$ 7.4) and resuspended in the same buffer up to $\mathrm{OD}_{360 \mathrm{~nm}}=0.07$. $\mathrm{DPH}$ was added to the cell suspensions at a final concentration of $0.2 \mu \mathrm{M}$ and its fluorescence was collected $40 \mathrm{~min}$ after incubation at $37{ }^{\circ} \mathrm{C}$ (determined insertion time). Steady state fluorescence was measured by a Perkin Elmer LS45 spectrofluorimeter with excitation and emission respectively at $360 \mathrm{~nm}$ and $450 \mathrm{~nm}$ (bandwidth $10 \mathrm{~nm}$ ).

\subsection{FT-IR microspectroscopy}

Intact $E$. coli cells were recovered from the fermentation broth (1-2 mL), centrifuged $\left(5000 \mathrm{rpm}, 15 \mathrm{~min}, 4{ }^{\circ} \mathrm{C}\right)$, rinsed, and resuspended in water. $10 \mu \mathrm{L}$ of this suspension were deposited on an infrared transparent support of $\mathrm{BaF}_{2}$ and dried at room temperature for $30 \mathrm{~min}$. The FT-IR absorption spectra were acquired in transmission using the UMA 500 infrared microscope coupled to a FTS40A spectrometer (Bio-Rad, Digilab Division, Cambridge, MA, USA) in the range 4000-800 $\mathrm{cm}^{-1}$. A nitrogen cooled mercury cadmium-tellurium detector (narrow band, $250 \mu \mathrm{m}$ ) and the following conditions were employed: $2 \mathrm{~cm}^{-1}$ spectral resolution, $20 \mathrm{kHz}$ scan speed, $128-256$ scan co-additions, triangular apodization. By setting the microscope square diaphragm aperture to $100 \mu \mathrm{m} \times 100 \mu \mathrm{m}$, a high-quality spectrum was collected within a few minutes.

In order to better identify the absorption bands of the lipid components, the second derivative analysis of the spectra was performed after a 15 point smoothing using the Savitzky-Golay method (3rd polynomial, 13 smoothing points) using the GRAMS/32 software (Galactic Industries Corporation, USA).

The FT-IR characterization of standard lipids purchased by Sigma was performed in attenuated total reflection on a single reflection 
a)

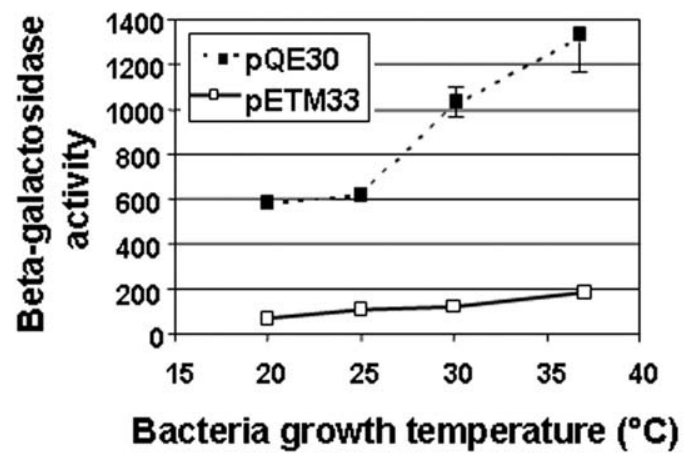

b)

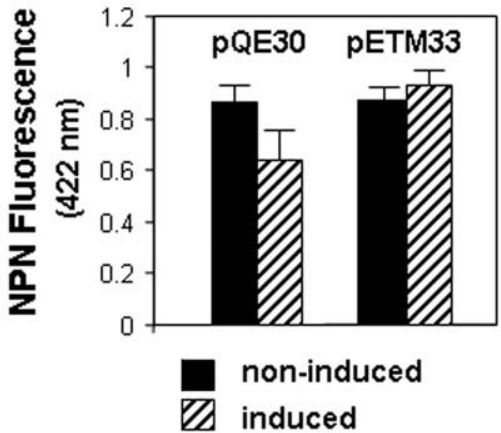

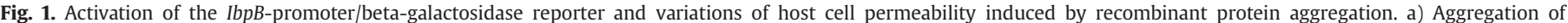

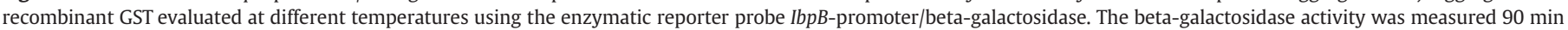

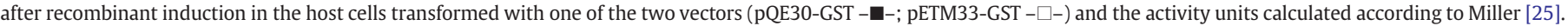

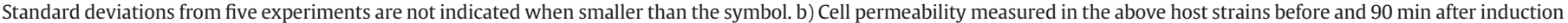
of GST expression at $37^{\circ} \mathrm{C}$. Data from three experiments.

diamond element (Golden Gate, Specac, UK) using the FTS40A spectrometer with a deuterated triglycine sulphate detector under the following conditions: $2 \mathrm{~cm}^{-1}$ spectral resolution, $5 \mathrm{kHz}$ scan speed, 256 scan co-additions, triangular apodization.

In the figures, we reported the measured spectra of one representative experiment. Standard deviation of peak position from three independent experiments was about $0.5 \mathrm{~cm}^{-1}$, while standard deviation of band intensity was about $2 \%$.

\section{Results}

\subsection{Membrane lipid modifications induced by recombinant protein} aggregation

To study the effects of recombinant protein aggregation on the cell membrane, we compared bacterial model systems expressing recombinant GST at different rates and monitored its aggregation using a specific probe, the $I b p B$-promoter/beta-galactosidase reporter [11,19]. The promoter of such a probe is specifically triggered by misfolded proteins undergoing aggregation [11,19]. In strains co-transformed with vectors carrying the probe and a sequence coding for a recombinant protein, the activity of beta-galactosidase indirectly enables to evaluate the level of recombinant protein misfolded and aggregated. In this system, we found that the recombinant GST protein was expressed mainly in the native form when bacteria, transformed with pETM33-GST vector, were kept for $90 \mathrm{~min}$ at temperatures between $20^{\circ} \mathrm{C}$ and $37{ }^{\circ} \mathrm{C}$, after induction of the T7 promoter (Fig. 1a). In contrast, GST was found to aggregate in bacteria kept at temperatures above $25{ }^{\circ} \mathrm{C}$, when the T5-promoter pQE30-GST vector was employed (Fig. 1a) [19].

The permeability of the cell membrane was measured in the two expression systems $90 \mathrm{~min}$ after induction at $37^{\circ} \mathrm{C}$ by means of a NPN fluorescent probe $[15,26]$ (Fig. 1b). The permeability did not significantly change in the strain hosting soluble GST (from pETM33), while it slightly decreased of about $25 \%$ after induction in the strain characterized by high GST misfolding and aggregation (from pQE30).

The overall changes in membrane lipids were detected by TLC [27]. No significant variation was found in cells producing soluble GST from pETM33, whilst some alterations were observed in the strain expressing aggregated GST from pQE30, such as an increase of about $20 \%$ in the phosphatidyl glycerol content (data not shown). Although the lack of reliable standards for $E$. coli lipids didn't allow the identification of the specific molecules involved in this rearrangement, this analysis provided general hints that changes in the membrane lipids occur under aggregation stress.
In conclusion, it was found that the stress due to recombinant protein misfolding and aggregation induces a reduction of permeability and a change in the lipid content of the cell membranes.

\subsection{Membrane lipid modifications detected by FT-IR spectroscopy}

Modifications in the cell membranes were also analyzed by FT-IR spectroscopy. The absorption of infrared radiation by lipids enables to identify their chemical bonds, such as $\mathrm{CH}_{2}, \mathrm{CH}_{3}, \mathrm{CH}$, and $\mathrm{C}=\mathrm{O}$ and, therefore, to monitor their structural modifications [30]. The lipid absorption bands in the $1220-1468 \mathrm{~cm}^{-1}$ region have been assigned in

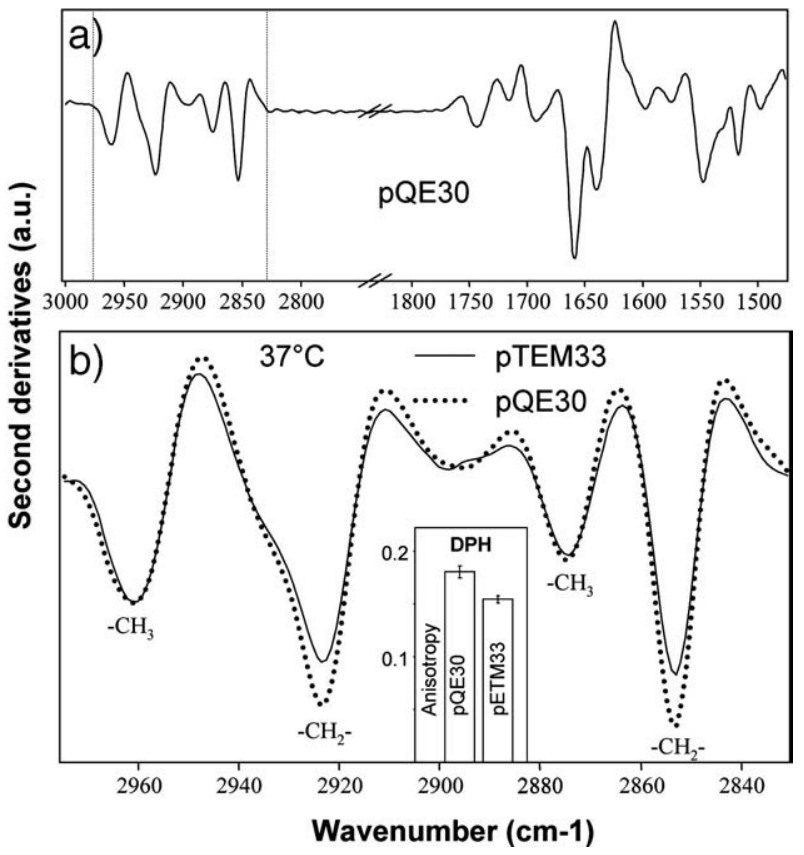

Fig. 2. FT-IR spectra of intact bacterial cells expressing recombinant GST. a) Second derivative FT-IR spectrum of E. coli intact cells transformed with the PQE30-GST vector, 90 min after induction at $37^{\circ} \mathrm{C}$. b) Second derivative FT-IR spectra in the $\mathrm{CH}$ stretching region of host cells transformed with pETM33-GST $(-)$ and pQE30-GST (...) vectors, 90 min after recombinant induction at $37^{\circ} \mathrm{C}$. GST aggregation occurs at low and high levels, respectively, in the host cells transformed with pETM33-GST and pQE30-GST vectors. For comparison, derivative spectra were normalized at the $2956 \mathrm{~cm}^{-1} \mathrm{CH}_{3}$ band. In the inset, the DPH fluorescence anisotropy for the above host cells, $90 \mathrm{~min}$ after induction at $37^{\circ} \mathrm{C}$, is reported. 
in vitro studies [21,31]. However, the most useful infrared response for the study of lipids in intact cells is that of the $\mathrm{CH}, \mathrm{CH}_{2}$, and $\mathrm{CH}_{3}$ bonds between $3050 \mathrm{~cm}^{-1}$ and $2800 \mathrm{~cm}^{-1}$, since no important absorption bands of other cell components overlap in this region. The infrared absorption spectra of standard lipids in the above mentioned spectra regions are reported in the Supplementary Fig. 1.

In Fig. 2, the second derivatives of the FT-IR absorption spectra of the E. coli host cells, transformed with pETM33-GST and pQE30-GST vectors, are reported. This mathematical procedure, widely used to resolve overlapping bands, allows identification of the different components in the absorption spectrum [32]. Furthermore, the relative weight of these components can be evaluated by the intensity of the negative peaks in the second derivative spectrum [32]. In Fig. 2a, the second derivative spectrum of the host cells is presented in the lipid absorption region from 3050 to $2800 \mathrm{~cm}^{-1}$, as well as in the protein Amide I and Amide II region from 1700 to $1500 \mathrm{~cm}^{-1}$. These last bands reflect the protein secondary structures and their intermolecular interactions [32,33] and have been extensively examined for the study of protein aggregation in vivo [34-39]. In the present work we extended the FT-IR investigation to the lipid absorption due to acyl chains, in particular the two $\mathrm{CH}_{2}$ peaks around $2923 \mathrm{~cm}^{-1}$ and $2853 \mathrm{~cm}^{-1}$, respectively assigned to asymmetric and symmetric stretching vibrations $[21,30,40]$.

In Fig. $2 \mathrm{~b}$ the second derivative spectra of host cells producing, at $37^{\circ} \mathrm{C}$, GST in soluble native form (pETM33) and in form of aggregates (pQE30) are reported. In presence of aggregation, we observed a higher intensity of the $\mathrm{CH}_{2}$ bands in the spectrum of pQE30-GST transformed cells (Fig. 2b). This increased intensity reflects the presence of longer and/or more saturated acyl chains that can be responsible for a decreased membrane permeability (Fig. 1b) and fluidity $[21,41]$. This last hypothesis was supported by measurements of DPH fluorescence anisotropy of the two strains, 90 min after induction (inset of Fig. 2b). pQE30-GST transformed cells displayed a higher value of anisotropy than pETM33-GST cells, corresponding to a lower membrane fluidity [42].

The direct relationship between increased stress due to recombinant protein misfolding and aggregation and a higher intensity of the $\mathrm{CH}_{2}$ lipid marker bands was confirmed by the comparison of the spectral response of pQE30-GST cells grown at $37{ }^{\circ} \mathrm{C}$ and at $20{ }^{\circ} \mathrm{C}$ (Supplemental Fig. 2a). The higher $\mathrm{CH}_{2}$ band was observed at the highest expression temperature, when the $\mathrm{IbpB}$-promoter/betagalactosidase reporter is strongly activated, indicating higher aggregate accumulation (Fig. 1a).

It is interesting to compare these results with those obtained in other model systems such as E. coli expressing Pseudomonas fragi lipase (PFL) at $27^{\circ} \mathrm{C}$ and $37^{\circ} \mathrm{C}$ [36] (Suppl. Fig. 2b). In this case the $\mathrm{CH}_{2}$ band intensity was lower at the highest temperature when the protein is expressed only in form of inclusion bodies (IBs), as it will be discussed later.

\subsection{Host protein variations induced by recombinant protein aggregation}

The effect of recombinant proteins expression on the host cell metabolism has been widely investigated [1]. However, no particular attention has been devoted to the relationship between the physical state of the recombinant proteins and the host cell metabolism. We, therefore, decided to explore whether such metabolic modifications correlate with the accumulation and the physical state of the recombinant protein aggregates. To this aim, we studied a strain expressing a GFP-GST construct that accumulates in aggregates, the complexity of which can be tuned modifying the growth temperature [9]. 1D and 2D gel electrophoresis of recombinant bacteria expressing GFP-GST in either soluble or aggregated form were examined and proteins identified by mass spectrometry.

The accumulation of recombinant aggregates was found to induce changes in the content of specific proteins involved in energy
Table 1

Variations of host cell protein content during the recombinant expression of GFP-GST

\begin{tabular}{|c|c|c|c|c|}
\hline \multirow[t]{4}{*}{ Host proteins } & \multicolumn{4}{|c|}{ Content variations (\%) } \\
\hline & \multirow{2}{*}{\multicolumn{2}{|c|}{$\begin{array}{l}20^{\circ} \mathrm{C} \\
\text { Hours after } \\
\text { induction }\end{array}$}} & \multirow{2}{*}{\multicolumn{2}{|c|}{$\begin{array}{l}37^{\circ} \mathrm{C} \\
\text { Hours after } \\
\text { induction }\end{array}$}} \\
\hline & & & & \\
\hline & $1 \mathrm{~h}$ & $7 \mathrm{~h}$ & $\overline{1 \mathrm{~h}}$ & $7 \mathrm{~h}$ \\
\hline Dihydrolipoyl dehydrogenase $\left(E_{3}\right)$ & $104 \pm 7$ & $105 \pm 14$ & $317 \pm 58$ & $102 \pm 11$ \\
\hline Glycerophosphoryl-diester phosphodiesterase & $47 \pm 9$ & $98 \pm 19$ & $27 \pm 6$ & $40 \pm 8$ \\
\hline OmpA & $331 \pm 38$ & $186 \pm 41$ & $526 \pm 77$ & $389 \pm 66$ \\
\hline IbpB & $168 \pm 31$ & $93 \pm 6$ & $430 \pm 60$ & $89 \pm 15$ \\
\hline SOD & $99 \pm 16$ & $98 \pm 7$ & $479 \pm 39$ & $116 \pm 28$ \\
\hline
\end{tabular}

Protein content variations were evaluated from spots separated by 2D gel and identified by mass spectrometry of recombinant and wild type bacteria. OmpA variations were evaluated from the intensity of Coomassie stained bands separated in 1D SDS-PAGE and measured by densitometry. E. coli cells were examined 1 and $7 \mathrm{~h}$ after recombinant induction, grown at $20^{\circ} \mathrm{C}$ and at $37^{\circ} \mathrm{C}$. Content variations are expressed as percentage of the values in non-induced cells (100\%). Data are from three independent experiments.

metabolism, transcription, folding, and quality control (data not shown), as previously reported in literature for other recombinant systems $[1,43]$.

In addition, in our work we report that the intracellular levels of some specific proteins - listed in Table 1 - were found to change significantly after induction of the recombinant protein in the strain grown at $20{ }^{\circ} \mathrm{C}$ as well as at $37{ }^{\circ} \mathrm{C}$. In particular, IbpB is a known marker of protein aggregation [13], OmpA is one of the major membrane proteins [44], dihidrolipoyl dehydrogenase $\left(E_{3}\right)$ and glycerophosphoryl-diester phosphodiesterase are involved in the lipid and antioxidant metabolism [45]. The accumulation of superoxide dismutase (SOD) further suggests a transient oxidative stress (Table 1).

These results, therefore, indicate that recombinant protein aggregation affects the expression of host proteins involved in lipid metabolism and oxidative stress in the GFP-GST model system examined here.

\subsection{Time course of GFP-GST aggregation and correlation with host protein and membrane modifications}

In an attempt to correlate the variations in the host proteins with the GFP-GST misfolding and aggregation, we followed in parallel the evolution of the protein levels (Table 1) and of the complexity of aggregates detected by electron microscopy (EM) and by the activation of the $I b p B$ promoter (Fig. 3).

The level of the host proteins reported in Table 1 displayed a maximum variation in the first hour after GFP-GST induction and reached again their initial value $7 \mathrm{~h}$ later. In particular, the variation of the IbpB concentration estimated by densitometry on the $1 \mathrm{D}$ and $2 \mathrm{D}$ gels (Table 1 ) was confirmed by the $I b p B$-promoter-dependent betagalactosidase activity (Fig. 3). In fact, the IbpB concentration increased in the first hour after the GFP-GST expression induction and then decreased during the following $6 \mathrm{~h}$ (Table 1 ).

The time dependence of the beta-galactosidase activity reported in Fig. 3 indicated a rapid increase of protein misfolding [11] soon after GFP-GST induction, followed by a significant decrease in the next $6 \mathrm{~h}$ (Fig. 3). However, when the time course of betagalactosidase activity is compared with IB formation (Fig. 3), an inverse correlation is observed, suggesting that misfolded proteins are entrapped in IBs. To better characterize this behaviour, the physical state of the protein $6 \mathrm{~h}$ after induction was investigated by EM (Fig. 3). Interestingly, not only insoluble structured nets were observed, but also small aggregates were found in the soluble fraction, showing the formation of soluble aggregates, as previously reported for the same system [9]. These results, therefore, indicated that the $I b p B$-promoter/beta-galactosidase reporter is activated in presence of the misfolded protein as well as of the soluble protein 


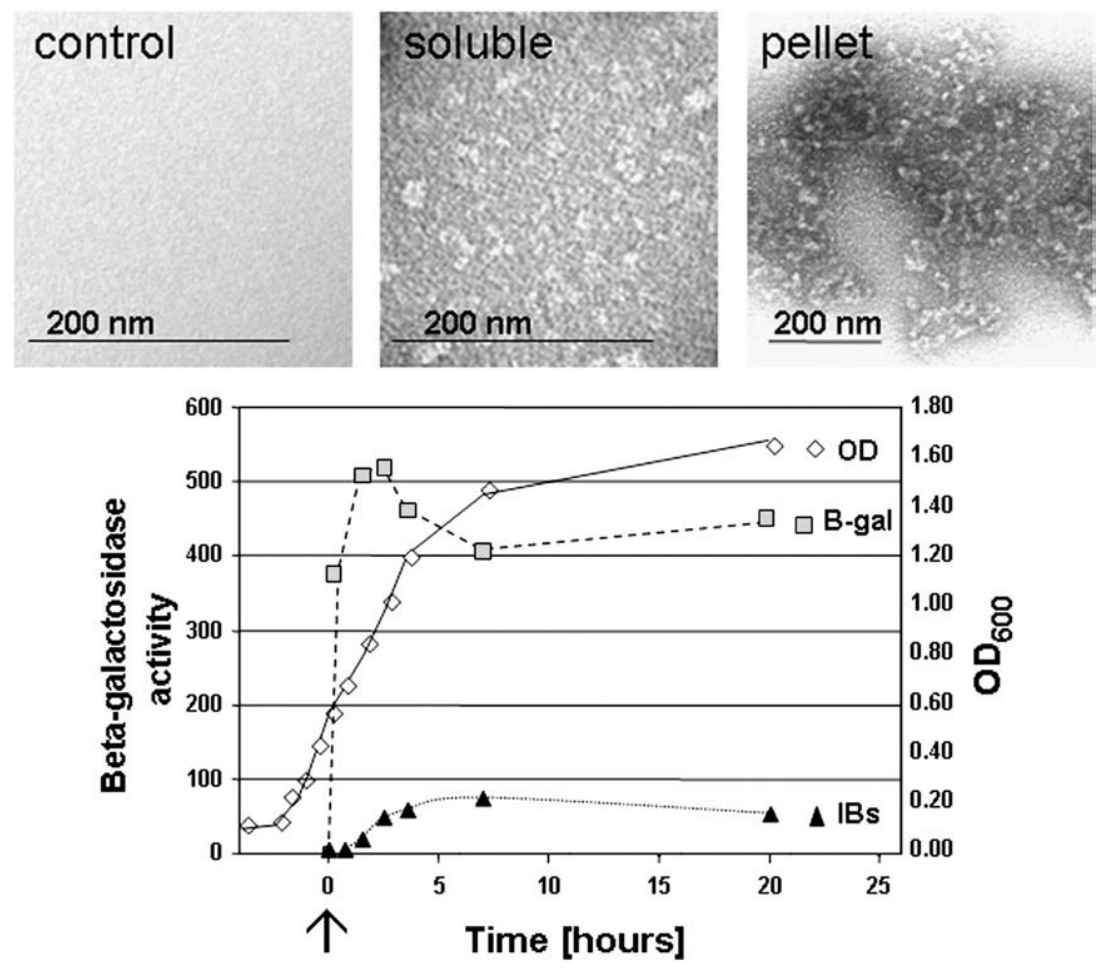

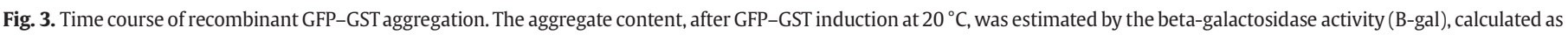

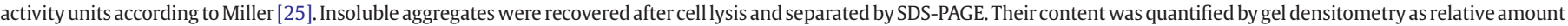

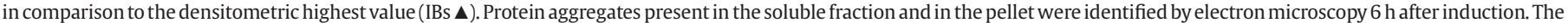

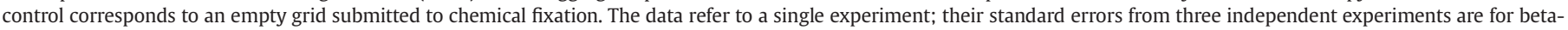
galactosidase activity about 30 units and for IB about $7 \%$. The $\mathrm{OD}_{600}(\diamond)$ of the bacterial cell culture grown at $20{ }^{\circ} \mathrm{C}$ was measured for 24 h. The arrow indicates the time of induction.

aggregates. This behaviour can be explained suggesting a possible model of aggregation of the recombinant protein: soon after induction, misfolded GFP-GST forms first soluble aggregates capable to activate the $\operatorname{IbpB}$ promoter -, which then precipitate into insoluble IBs. These, in turn, are slowly partially disrupted in the final phase of the cell culture. Indeed, we found a reduction of insoluble aggregates (IBs) between 7 and $20 \mathrm{~h}$ after induction, as shown in Fig. 3. In this last interval of time, we observed also a simultaneous increase of beta-galactosidase activity, suggesting that part of the protein released from IBs can be found in a misfolded form and in soluble aggregates.

The time dependence of the biochemical response presented above was found to be in agreement with the host cell lipid modifications monitored by FT-IR spectroscopy (Fig. 4). The intensity of the two $\mathrm{CH}_{2}$ components slightly increased $1 \mathrm{~h}$ after induction and decreased to a minimum value after six more hours, namely at the moment of minimum soluble aggregate content and maximal insoluble protein accumulation (Figs. 3 and 4, inset). The infrared $\mathrm{CH}_{2}$ bands increased again between 7 and $24 \mathrm{~h}$, simultaneously with the decrease of insoluble aggregates and the increase of the betagalactosidase activity (Figs. 3 and 4). We should note that the intensity of the two $\mathrm{CH}_{2}$ peaks at $2923 \mathrm{~cm}^{-1}$ and $2853 \mathrm{~cm}^{-1}$, assigned respectively to the asymmetric and symmetric $\mathrm{CH}_{2}$ stretching modes of lipid acyl chains, changed always in accordance at the same time, further supporting the significance of the spectral response.

The temporal evolution of host protein levels (Table 1), IB formation and $I b p B$-promoter-dependent beta-galactosidase activity (Fig. 3), indicate, therefore, that misfolded protein and soluble aggregates (but not the soluble native protein nor IBs) are responsible for the stress-dependent modification of the level of the host proteins and for the activation of the $I b p B$-promoter/beta-galactosidase reporter. Furthermore, the intensity variation of the $\mathrm{CH}_{2}$ infrared bands was found to be correlated not with the presence of IBs, but rather with that of the misfolded protein and soluble aggregates, probed by the $I b p B$-promoter/beta-galactosidase reporter.

\section{Discussion}

The present study on bacteria expressing recombinant proteins in native, misfolded, and aggregated form indicates that protein

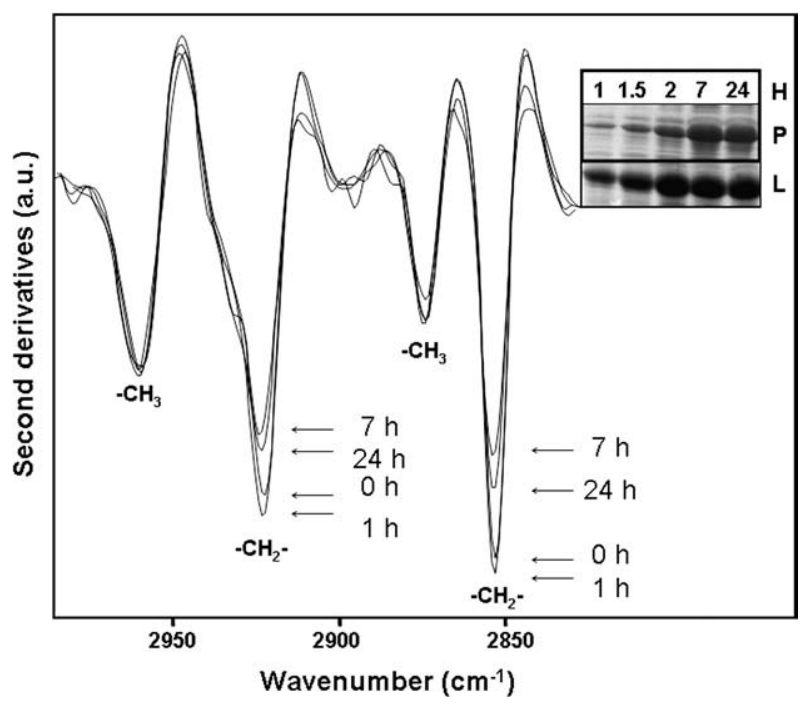

Fig. 4. Lipid modifications during the expression of recombinant GFP-GST monitored by FT-IR spectroscopy. Second derivative absorption spectra of intact cells expressing GFPGST, immediately and 1,7 , and $24 \mathrm{~h}$ after induction at $20^{\circ} \mathrm{C}$. Derivative spectra were normalized at the $2956 \mathrm{~cm}^{-1} \mathrm{CH}_{3}$ band. The inset shows the SDS-PAGE of GFP-GST samples recovered at different times ( $\mathrm{H}$ : hours) after induction: insoluble fraction $(\mathrm{P})$ and total lysate (L). 
misfolding and aggregation lead to a significant reorganization of the cell membrane, as well as of the host protein expression, sharing several features with other stress responses.

Interestingly, some of the host proteins whose level is affected by aggregation of the recombinant protein could be involved in lipid metabolism (Table 1). Indeed, small heat shock proteins like IbpB, known as protein aggregation markers [13], were found to stabilize cell membranes and to modulate their polymorphism [21]. It has been suggested that the role of small heat shock proteins could be crucial in the initial stage of the response to stress conditions that can alter the membrane structure [21]. The folding of OmpA is strongly dependent on the properties of the lipid bilayer [46] and it has been reported to have a role in membrane stabilization $[44,47,48]$. In addition, the temporary accumulation of $\mathrm{E}_{3}$ could be an indication of a channelling of pyruvate into acetyl-CoA. Such a metabolite could be used not only for energetic needs, but also for lipid anabolism. In addition, $E_{3}$ is also involved in the antioxidant metabolism and, together with IbpB and SOD (Table 1), may participate in maintaining the membrane integrity preventing lipid peroxidation. Similarly to what happens in mammalian cells, the antioxidant activity of SOD could act together with the stabilizing and anti peroxidative activity of IbpB [49,50]. Summarizing, beside the classical activation of $\mathrm{IbpA} / \mathrm{B}$ chaperones, the accumulation of recombinant protein aggregates seems: a) to trigger a transient oxidative stress as suggested by the increased levels of SOD and $\mathrm{E}_{3}$; $\mathrm{b}$ ) to stabilize the host membrane and regulate the porin-mediated transport, as indicated by the lower fluidity and by the accumulation of OmpA. It would be also interesting to investigate, in the presence of aggregation, the behaviour of proteins known for their role in membrane stress, such as RseB and phage shock protein A, which are respectively involved in sensing membrane stress [51] and in maintaining the membrane potential [52].

We also found that protein misfolding and aggregation induce rearrangements of the membrane and lipid composition in the host cells. In particular, we found a reduction of the membrane permeability (as shown by NPN fluorescence) and of fluidity (indicated by DPH fluorescence anisotropy). This behaviour is similar to that determined by heat-shock or benzyl alcohol treatments, which induce a lower permeability of the membrane after an initial hyperfluidification [15]. Furthermore, lipid modifications were detected by TLC and by FT-IR spectroscopy. In particular, the increase of the $\mathrm{CH}_{2}$ infrared band intensities indicated the presence of longer and/or more saturated acyl chains under aggregation stress conditions.

The most striking understanding of the above observations can be derived from the comparison of the temporal evolution of the host protein levels (Table 1) and the lipid modifications (Fig. 4) with that of the aggregation process monitored by IB formation, EM, and IbpBpromoter-dependent beta-galactosidase activity (Fig. 3).

Indeed, all these results point out that misfolded protein and soluble aggregates (but not the soluble native protein nor IBs) activate the IbpBpromoter/beta-galactosidase reporter and are responsible for the membrane modifications and the changes in host protein levels.

Interestingly, native recombinant protein and large insoluble aggregates do not seem to appreciably activate stress markers (Table 1, Fig. 1a, Fig. 3) and membrane rearrangement (Fig. 1b, Fig. 2, Fig. 4, and Suppl. Fig. 2b).

In eukaryotic systems, pre-fibrillar aggregates, which have been found to be more toxic than large amyloids [8,53], are deposited into aggresomes to prevent their toxicity [54]. In this view, the possibility to store the overexpressed protein in insoluble aggregates could be a mechanism of the host cell to trap harmful species of misfolded proteins [8].

\section{Acknowledgments}

Scott Lesley (Novartis Research Foundation) kindly provided us with the $I b p B$-promoter/beta-galactosidase reporter; the Proteomic
Facility at the EMBL-Heidelberg performed the 2D and mass-spectrometry analyses. We are grateful to Carla Smeraldi for kindly revising the language. S.M.D. and M.L. acknowledge the financial support of the F.A.R. (Fondo d'Ateneo per la Ricerca) and A.N. the post-doctoral fellowship of the University of Milano-Bicocca (I).

\section{Appendix A. Supplementary data}

Supplementary data associated with this article can be found, in the online version, at doi:10.1016/j.bbapap.2008.10.015.

\section{References}

[1] F. Hoffmann, U. Rinas, Stress induced by recombinant protein production in Escherichia coli, Adv. Biochem. Engin./Biotechnol. 89 (2004) 73-92.

[2] A.P. Gasch, M. Werner-Washburne, The genomics of yeast responses to environmental stress and starvation, Funct. Integr. Genomics 2 (2002) 181-192.

[3] U. Sauer, D.R. Lasko, J. Fiaux, M. Hochuli, R. Glaser, T. Szyperski, K. Wüthrich, J.E. Bailey, Metabolic flux ratio analysis of genetic and environmental modulations of Escherichia coli central carbon metabolism, J. Bacteriol. 181 (1999) 6679-6688.

[4] Q. Hua, C. Yang, T. Oshima, H. Mori, K. Shimizu, Analysis of gene expression in Escherichia coli in response to changes of growth-limiting nutrient in chemostat cultures, Appl. Environ. Microbiol. 70 (2004) 2354-2366.

[5] A. Mogk, T. Tomoyasu, P. Goloubinoff, S. Rudiger, D. Roder, H. Langen, B. Bukau, Identification of thermolabile Escherichia coli proteins: prevention and reversion of aggregation by DnaK and ClpB, EMBO J. 18 (1999) 6934-6949.

[6] S. Diamant, N. Eliahu, L. Rosenthal, P. Goloubinoff, Chemical chaperones regulate molecular chaperones in vitro and in cells under combined salt and heat stresses, J. Biol. Chem. 276 (2001) 39586-39591.

[7] D. Mattanovich, B. Gasser, H. Hohenblum, M. Sauer, Stress in recombinant protein producing yeast, J. Biotechnol. 113 (2004) 121-135.

[8] M. Bucciantini, G. Calloni, F. Chiti, L. Formigli, D. Nosi, C.M. Dobson, M. Stefani, Prefibrillar amyloid protein aggregates share common features of cytotoxicity, J. Biol. Chem. 279 (2004) 31374-31382.

[9] A. Schrödel, A. de Marco, Characterization of the aggregates formed during recombinant protein expression in bacteria, BMC Biochem. 6 (2005) 10.

[10] N. Gonzalez-Montalban, E. García-Fruitós, A. Villaverde, Recombinant protein solubility-does more mean better? Nat. Biotechnol. 25 (2007) 718-720.

[11] S.A. Lesley, J. Graziano, C.Y. Cho, M.W. Knuth, H.E. Klock, Gene expression response to misfoded protein as a screen for soluble recombinant protein, Protein Eng. 15 (2002) 153-160.

[12] M.M. Carrió, A. Villaverde, Protein aggregation as bacterial inclusion bodies is reversible, FEBS Lett. 489 (2001) 29-33.

[13] J.A. Johnston, C.L. Wand, R.R. Kopito, Aggresomes: a cellular response to misfolded proteins, J. Cell Biol. 143 (1998) 1883-1898.

[14] A. de Marco, E. Deuerling, A. Mogk, T. Tomoyasu, B. Bukau, Chaperone-based procedure to increase yields of soluble recombinant proteins produced in E. coli, BMC Biotechnol. 7 (2007) 32.

[15] G. Balogh, I. Horvath, E. Nagy, Z. Hoyk, S. Benko, O. Bensaude, L. Vigh, The hyperfluidization of mammalian cell membranes acts as a signal to initiate the heat shock protein response, FEBS J. 272 (2005) 6077-6086.

[16] N. Shigapova, Z. Török, G. Balogh, P. Goloubinoff, L. Vigh, I. Horvath, Membrane fluidization triggers membrane remodeling which affects the thermotolerance in Escherichia coli, Biochem. Biophys. Res. Commun. 328 (2005) 1216-1223.

[17] S. Gudi, G.P. Nolan, J.A. Frangos, Modulation of GTPase activity of G proteins by fluid shear stress and phospholipid composition, Proc. Natl. Acad. Sci. U. S. A. 95 (1998) 2515-2519.

[18] C. Canale, S. Torrassa, P. Rispoli, A. Relini, R. Rolandi, M. Bucciantini, M. Stefani, A. Gliozzi, Natively folded HypF-N and its early amyloid aggregates interact with phospholipid monolayers and destabilize supported phospholipid bilayers, Biophys. J. 91 (2006) 4575-4588.

[19] T. Schultz, L. Martinez, A. de Marco, The evaluation of the factors that cause aggregation during recombinant expression in $E$. coli is simplified by the employment of an aggregation-sensitive reporter, Microb. Cell Fact. 5 (2006) 28.

[20] A. Mogk, E. Deuerling, S. Vorderwlbecke, E. Vierling, B. Bukau, Small heat shock proteins, $\mathrm{ClpB}$ and the DnaK system form a functional triade in reversing protein aggregation, Mol. Microbiol. 50 (2003) 585-595.

[21] N.M. Tsvetkova, I. Horvath, Z. Török, W.F. Wolkers, Z. Balogi, N. Shigapova, L.M. Crowe, F. Tablin, E. Vierling, J.H. Crowe, L. Vigh, Small heat-shock proteins regulate membrane lipid polymorphism, Proc. Natl. Acad. Soc. U. S. A. 99 (2002) 13504-13509.

[22] J.C. Bischof, W.F. Wolkers, N.M. Tsvetkova, A.E. Oliver, J.H. Crowe, Lipid and protein changes due to freezing in Dunning AT-1 cells, Cryobiology 45 (2002) 22-32.

[23] L. Beney, Y. Mille, P. Gervais, Death of Escherichia coli during rapid and severe dehydration is related to lipid phase transition, Appl. Microbiol. Biotechnol. 65 (2004) 457-464.

[24] A. Dümmler, A.-M. Lawrence, A. de Marco, Simplified screening for the detection of soluble fusion constructs expressed in E. coli using a modular set of vectors, Microb. Cell Fact. 4 (2005) 34

[25] J.H. Miller, A short course in bacterial genetics - a laboratory manual and handbook for Escherichia coli and related bacteria, Cold Spring Harbor Laboratory Press, Cold Spring Harbor New York, 1992, pp. 72-82. 
[26] I.M. Helander, T. Mattila-Sandholm, Fluorimetric assessment of gram-negative bacterial permeabilization, J. Appl. Microbiol. 88 (2000) 213-219.

[27] I.J. Cartwright, Separation and analysis of phospholipids by thin-layer chromatography, Methods Mol. Biol. 19 (1993) 153-167.

[28] J.R. Lakowicz, Principles of Fluorescence Spectroscopy, Kluwer-Plenum, New York, 1999.

[29] M. Schlame, I. Horvath, Z. Török, L.I. Horvath, L. Vigh, Intramembraneous hydrogenation of mitochondrial lipids reduces the substrate availability, but not the enzyme activity of endogenous phospholipase A. The role of polyunsaturated phospholipid species, Biochim. Biophys. Acta 1045 (1990) 1-8.

[30] I. Echabe, M.A. Requero, F.M. Goni, J.L. Arrondo, A. Alonso, An infrared investigation of palmitoyl-coenzyme A and palmitoylcarnitine interaction with perdeuterated-chain phospholipid bilayers, Eur. J. Biochem. 231 (1995) 199-203.

[31] H.L. Casal, H.H. Mantsch, Polymorphic phase behaviour of phospholipid membranes studied by infrared microscopy, Biochim. Biophys. Acta 779(1984) 381-401.

[32] H. Susi, D.M. Byler, Resolution-enhanced Fourier transform infrared spectroscopy of enzymes, Methods Enzymol. 130 (1986) 290-311.

[33] A. Natalello, R. Santarella, S.M. Doglia, A. de Marco, Physical and chemica perturbations induce the formation of protein aggregates with different structural features, Protein Expr. Purif. 58 (2008) 356-361.

[34] D. Ami, L. Bonecchi, S. Calì, G. Orsini, G. Tonon, S.M. Doglia, FT-IR study of heterologous protein expression in recombinant Escherichia coli strains, Biochim. Biophys. Acta 1624 (2003) 6-10.

[35] D. Ami, A. Natalello, G. Taylor, G. Tonon, S.M. Doglia, Structural analysis of protein inclusion bodies by Fourier transform infrared microspectroscopy, Biochim. Biophys. Acta 176 (2006) 793-799.

[36] D. Ami, A. Natalello, P. Gatti-Lafranconi, M. Lotti, S.M. Doglia, Kinetics of inclusion body formation studied in intact cells by FT-IR spectroscopy, FEBS Lett. 579 (2005) 3433-3436.

[37] N. Gonzalez-Montalban, A. Natalello, E. García-Fruitós, A. Villaverde, S.M. Doglia In situ protein folding and activation in bacterial inclusion bodies, Biotechnol Bioeng. 100 (2008) 797-802.

[38] S.M. Doglia, D. Ami, A. Natalello, P. Gatti-Lafranconi, M. Lotti, Fourier transform infrared spectroscopy analysis of the conformational quality of recombinant proteins within inclusion bodies, Biotechnol. J. 3 (2008) 193-201.

[39] S. Gross-Selbeck, G. Margreiter, C. Obinger, K. Bayer, Fast quantification of recombinant protein inclusion bodies within intact cells by FT-IR spectroscopy, Biotechnol. Prog. 23 (2007) 762-766.

[40] L.K. Tamm, S.A. Tatulian, Infrared spectroscopy of proteins and peptides in lipid bilayers, Q. Rev. Biophys. 30 (1997) 365-429.
[41] H.G. Yuk, D.L. Marshall, Heat adaptation alters Escherichia coli 0157:H7 membrane lipid composition and verotoxin production, Appl. Environ. Microbiol. 69 (2003) 5115-5119.

[42] Z. Gyorfy, I. Horvath, G. Balogh, A. Domonkos, E. Duda, B. Maresca, L. Vigh, Modulation of lipid unsaturation and membrane fluid state in mammalian cells by stable transformation with the delta9-desaturase gene of Saccharomyces cerevisiae, Biochem. Biophys. Res. Commun. 237 (1997) 362-366.

[43] D. Böhm, U. Rinas, Comparative transcriptional profiling of the bacterial stress response in temperature and chemically-induced recombinant E. coli process, Microb. Cell Fact. 5 (2006) P1.

[44] E. Sugawara, H. Nikaido, Pore-forming activity of OmpA protein of Escherichia coli, J. Biol. Chem. 267 (1992) 2507-2511.

[45] T. Nordman, L. Xia, L. Bjorkhem-Bergman, A. Damdimopoulos, I. Nalvarte, E.S. Arner, G. Spyrou, L.C. Eriksson, M. Bjornstedt, J.M. Olsson, Regeneration of the antioxidant ibiquinol by lipoamide dehydrogenase, thioredoxin reductase and glutathione reductase, Biofactors 18 (2003) 45-50.

[46] H. Hong, L.K. Tamm, Elastic coupling of integral membrane protein stability to lipid bilayer forces, Proc. Natl. Acad. Soc. U. S. A. 101 (2004) 4065-4070.

[47] I. Sonntag, H. Schwartz, Y. Hirota, U. Henning, Cell envelope and shape of Escherichia coli: multiple mutants missing the outer membrane lipoprotein and other major outer membrane proteins, J. Bacteriol. 136 (1978) 280-285.

[48] Y. Wang, The function of OmpA in Escherichia coli, Biochem. Biophys. Res. Commun. 292 (2002) 396-401.

[49] C.-Y. Su, K.-Y. Chong, K. Edelstein, S. Lille, R. Khardori, C.-C. Lai, Constitutive hsp70 attenuates hydrogen peroxide-induced membrane lipid peroxidation, Biochem. Biophys. Res. Commun. 265 (1999) 279-284.

[50] P.S. Ray, J.L. Martin, E.A. Swanson, H. Otani, W.H. Dillmann, D.K. Das, Transgene overexpression of alphaB crystallin confers simultaneous protection against cardiomyocyte apoptosis and necrosis during myocardial ischemia and reperfusion, FASEB J. 15 (2001) 393-402.

[51] P. Wollmann, K. Zeth, The structure of RseB: a sensor in periplasmic stress response of E. coli, J. Mol. Biol. 372 (2007) 927-941.

[52] R. Kobayashi, T. Suzuki, M. Yoshida, Escherichia coli phage-shock protein A (PspA) binds to membrane phopsholipids and repairs proton leakage of the damaged membranes, Mol. Microbiol. 66 (2007) 100-109.

[53] R. Kayed, E. Head, J.L. Thompson, T.M. McIntire, S.C. Milton, C.W. Cotman, C.G. Glabe, Common structure of soluble amyloid oligomers implies common mechanism of pathogenesis, Science 300 (2003) 486-489.

[54] R.R. Kopito, Aggresomes, inclusion bodies and protein aggregation, Trends Cell Biol. 10 (2000) 524-530. 